\title{
DON LUIS CIFUENTES, MAESTRO Y ESCRITOR
}

\author{
Francisco José Díaz Alférez
}

Servicio de Urología. Hospital Clínico Universitario. Salamanca. España.

Resumen.- En el centenario del Dr. Luis Cifuentes se relatan diversas anécdotas sobre su faceta docente, que ayudan a conocer y a entender su calidad profesional y humana.

Palabras clave: Historia. Centenario. Luis Cifuentes Delatte.

Summary.- In the centenary of Dr. Luis Cifuentes Delatte we tell several histories about his teaching, which help to know and understand his professional and human quality.

Keywords: History. Centenary. Dr. Luis Cifuentes Delatte.

\section{INTRODUCCIÓN}

Cuando se cumple el centenario de D. Luís Cifuentes Delatte y se me invita a escribir unas líneas en su memoria, he decidido -aún pecando de centrarme en lo anecdótico- ajustarme tan sólo a las vivencias acaecidas a su lado durante mis años de formación en la Fundación Jiménez Díaz de Madrid, eludiendo pues, repetir una vez más su conocida biografía profesional.

Sé que su trayectoria y su currículum son conocidos por casi todos nosotros y en éstas particulares fechas serán nuevamente divulgados para los mas jóvenes, por plumas mucho mas autorizadas que la mía personal.

Pero los que hemos tenido el honor de formar parte de su última promoción de Médicos Residentes, nunca olvidaremos su diaria cercanía en la docencia y su enorme capacidad de transmitirnos ilusión en el estudio urológico del paciente renal.

Don Luís -como cariñosamente le llamábamos- supo ser -aún en sus últimos años- un auténtico maestro que logró trasladarnos su particular pasión por el estudio de la orina al microscopio, la investigación de la litiasis, la endoscopia urológica y todo cuanto significaba desarrollo e investigación en nuestra especialidad.

Las sesiones clínicas siempre fueron bajo sus auspicios un foro donde adquirir criterios clínicos y un acicate para profundizar en el aprendizaje y la revisión bibliográfica de la entidad nosológica sobre la que versaba la discusión.

Estar "detrás de su hombro" en una sesión de cirugía endoscópica era para todos nosotros un absoluto privilegio no solo por acceder a la visión 
directa por la óptica de enseñanza, como por poder participar en la observación de su estrategia quirúrgica y sus personales comentarios sobre la intervención.

Fue en esta época de nuestra Residencia cuando al intentar trasmitirnos la sensación especial de precisión al pie derecho que ha de poseer un buen endoscopista, surgió el comentario jocoso de "pie de elefante" que le animamos a incluir en Cirugía Urológica Endoscópica en la última edición.

Porque al doctor Cifuentes Delatte no solo había que observarle y escucharle. Era tan gratificante como necesario también leerle, cosa que todos hacíamos con auténtica devoción.

Siempre fue don Luís un escritor científico muy riguroso y extraordinariamente culto. Pero sobre todo y ante todo era un escritor deliciosamente ameno en su descripción.

Podía sin duda afirmarse que la portentosa agilidad de su pluma compensaba con creces una sutil -a veces inapreciable- congénita torpeza en la dicción. Sus escritos presentaban una sencillez de exposición tan solo aparente, pues don Luis los limaba, pulía y mejoraba una y otra vez, hasta la saciedad.

En una ocasión en que preparaba una ponencia y me concedió el honor de poder acceder al borrador de la misma, ante mi pregunta de porque le estresaba su confección y corrección precisamente a él, que había escrito ya tantos libros, me confesó:

"Querido Díaz Alférez algún día comprenderás que es más estresante un trabajo solicitado que un libro, sobre todo si te exiges una rigurosa redacción. En las ponencias yo lucho siempre contra el tiempo porque la fecha me viene impuesta y el plazo se ha de cumplir inexorablemente. En los libros todo es mucho más sencillo: jel punto final solo lo marco yo!"

Comprendí perfectamente cómo mi jefe detestaba en cuestión de literatura cuanto pudiera suponer desaliño e improvisación.

El profesor Cifuentes odiaba que se fotocopiase cualquier libro de texto. Opinaba que suponía una traición a la editorial y un robo al autor, y por ello desistíamos de tales prácticas, al menos en su presencia.

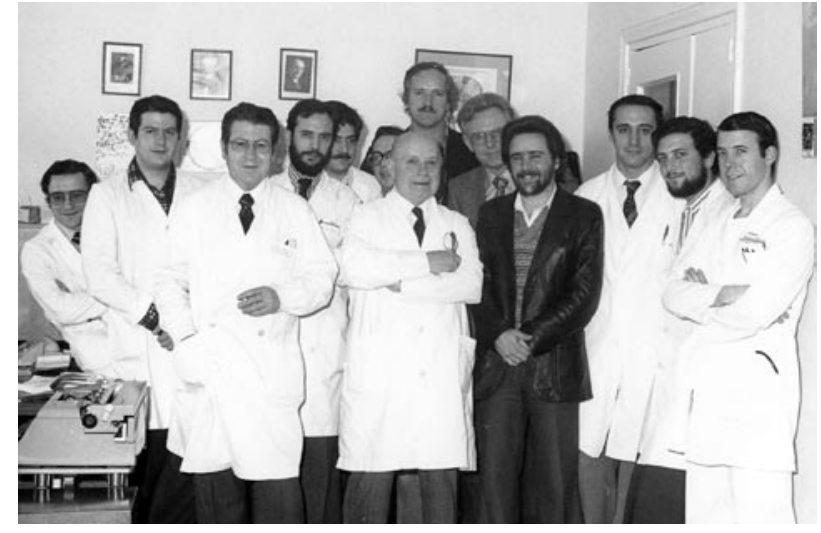

FIGURA 1. Don Luis Cifuentes Delatte posa junto a los miembros de su Servicio en el año 1976, con motivo de la visita a nuestro departamiento de una comisión de doctores desde Brasil. Con bata blanca y de izquierda a derecha: Dres. Miñón Cifuentes, Díaz Alférez, Alférez Villalobos, García de la Peña, Grunfeld Avellán, Salinas Casado, Cifuentes Delatte, Escudero Callén, Fernández Puentes y Jiménez Navarro.

Pero el hecho es que yo quería estudiar el libro de "Cistitis y Cistopatías" y la prometida nueva edición no tenia visos de llegar nunca a salir...

Así pues logré que me lo prestara el Dr. García de la Peña y -antes de devolvérselo- lo fotocopié en su totalidad. Fue para mi sorpresa que días mas tarde estudiando en el despacho del Servicio, entró nuestro jefe inopinadamente, centrando al momento su mirada en mi flamante ejemplar. Observó mi rubor mientras lo cogía entre sus manos -perfectamente encuadernado- y ante mi sorpresa se dispuso a escribir varios renglones bajo el titulo principal.

Una vez que lo hubo firmado se acercó de nuevo a devolvérmelo y con un guiño de cómica complicidad me espetó:

"A esta nueva edición -de un ejemplar únicole faltaba aún el prólogo del autor: Ahora ya si que es completamente legal"...

El centenario del nacimiento de $\mathrm{D}$. Luís $\mathrm{Ci}$ fuentes Delatte marca también los tres años de su desaparición. Pero su extraordinaria personalidad humana y científica ha dejado ya una impronta indeleble entre todos los que tuvimos la gran suerte de considerarnos sus alumnos y a cuantos en vida nos distinguió con su afecto y amistad. 